\title{
Early Diagnosis and Screening of Oral Cancers
}

\section{Sundaram Rajaram* and Gauthami Sundar}

Department of Oral and Maxillofacial Surgery, Rajaram's Dental Surgery, India

*Corresponding Author: Sundaram Rajaram, Department of Oral and

Maxillofacial Surgery, Rajaram's Dental Surgery, India.
Received: June 09, 2021

Published: June 25, 2021

(C) All rights are reserved by Sundaram

Rajaram and Gauthami Sundar.

\begin{abstract}
Oral cancer forms an important aspect of cancer and contributes to cancer deaths in a sizeable numbers. More often than less the delay in cancer diagnosis and initiation of treatment lead to deaths. For delay in each unit of time the worse are the consequences of cancer and treatment prognosis. It is therefore important to identify the cancer at the very inception and start the treatment when it can last effectively. This article discusses the new strategies in approaching such oral cancers, namely 'Early diagnosis' and 'Screening'.
\end{abstract}

Keywords: Oral Cancers; Screening; Early Diagnosis

\section{Introduction}

About 657,000 new cases of oral cancer cases are estimated and 330,000 deaths happened due to oral cancers [1]. This alarming rise in number of cases and deaths require serious attention. Immense healthcare efforts of curbing the habitual causes of oral cancers by way of public awareness are being done in full swing. Apart from health education the need for additional measures has become mandatory. This calls for a comprehensive approach to manage the oral cancer patients thereby reducing the risk factors and worse consequences of the disease.

This article highlights about two important entities in the approach to comprehensive cancer treatment - 'Early diagnosis' and 'Cancer screening'

What is early diagnosis?

Early diagnosis is defined as the early identification of cancer in patients who have symptoms of the disease [2].

When the signs and symptoms become consistent with cancer, the early diagnosis come into play. This is an intervention in people having symptoms of oral cancers and are subjected to prompt investigation for the final diagnosis and start of the appropriate treatment. Thus, the objective is to identify the disease and link the diagnosis to the treatment sequences thus dealing with the disease in a potentially curative intent. The early diagnosis involves a stepwise approach to the cancer patients:

- $\quad$ Step 1: Spreading awareness of cancer.

- $\quad$ Step 2: Clinical evaluation, diagnosis and staging; and

- $\quad$ Step 3: Treatment initiation and management [3] (Figure 1).

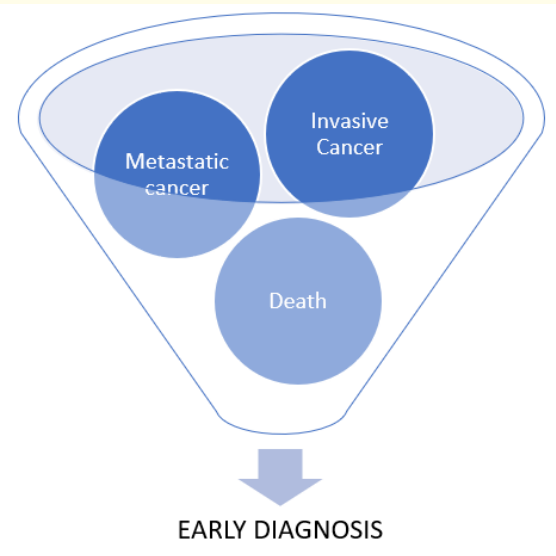

Service for symptomatic population

Figure 1 
What is cancer screening?

Cancer screening seeks to identify unrecognized (pre-clinical) cancer or pre-cancerous lesions in an apparently healthy target population [1].

Cancer screening aims to identify potential cancer patients who do not have full-fledged signs and symptoms. Such potential cancer patients are screened, identified and subjected to various investigations that are required to be done. Once screened and identified, the interventions include examinations like VIA (visual inspection with acetic acid), tests like HPV assay, imaging (Figure 2).

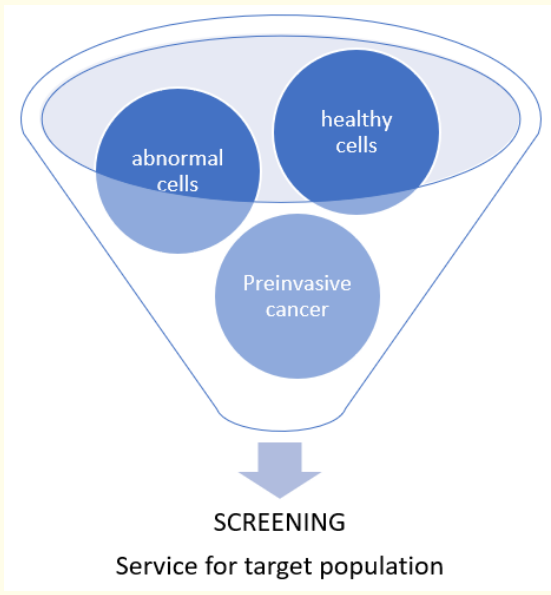

Figure 2
Similar to the early diagnosis, the cancer screening also involves a stepwise approach to the cancer patients:

- $\quad$ Step 1- Inviting the patients to participate in the screening program.

- $\quad$ Step 2-Screening evaluation.

- $\quad$ Step 3- Interpreting the test results and referral for further investigations among those with abnormal test results.

- $\quad$ Step 4- Establishing the pathologic diagnosis and referral to higher centre for effective treatment with routine evaluation to improve the process [3].

\section{Discussion}

In the context of dealing with oral cancers in a methodical fashion, early diagnosis and screening hit the lime light. Such measures involve the infrastructure, healthcare modalities, technicians and specialists which form the integral components in this comprehensive approach (Table 1) [2]. These resources can make early diagnosis and cancer screening effective strategical methods in curbing the mortalities associated with oral cancers [3].

It is a fact beyond doubt that early cancer diagnosis marks the beginning of curative intervention for the same [3]. Such strategies have produced remarkable results in other countries that have been following early diagnosis and screening. For instance, Great Britain has reduced the breast cancer mortality by $50 \%$ by following early diagnosis and screening strategies [4-7].

\begin{tabular}{|c|c|c|c|}
\hline S NO & Entities & Early diagnosis & Cancer screening \\
\hline 1 & Target population & Only symptomatic population & Entire target population \\
\hline 2 & Test procedures & Limited only to symptomatic individuals & $\begin{array}{c}\text { Screening test for entire population and } \\
\text { diagnostic tests only for positive screening } \\
\text { individuals }\end{array}$ \\
\hline 3 & $\begin{array}{c}\text { Healthcare require- } \\
\text { ments }\end{array}$ & $\begin{array}{c}\text { Healthcare infrastructure that facilitates the Diag- } \\
\text { nosis, Histopathology, Radiology, cancer staging and } \\
\text { access to prompt treatment }\end{array}$ & $\begin{array}{c}\text { Healthcare infrastructure for inviting and } \\
\text { screening tests, diagnostic tests and recall } \\
\text { mechanism }\end{array}$ \\
\hline 4 & $\begin{array}{c}\text { Healthcare person- } \\
\text { nel }\end{array}$ & $\begin{array}{c}\text { Should possess adequate training to diagnose and } \\
\text { investigate and treat oral cancer }\end{array}$ & $\begin{array}{c}\text { Early providers for screening tests. } \\
\text { Pathologists and biochemists for lab results } \\
\text { interpretation }\end{array}$ \\
\hline 5 & Public awareness & Reporting if any signs and symptoms & Participation in screening program \\
\hline 6 & Follow up care & Referral to higher centres for further management & Involves recall and counselling \\
\hline 7 & Benefits & Early stage detection and reduced mortality rate & Reduction in incidence and mortality rate \\
\hline 8 & Ill effects & Low- testing limited only to those with signs and \\
symptoms & $\begin{array}{c}\text { Requirement of additional tests for positive } \\
\text { individuals that can lead to complications and } \\
\text { psychological distress and resource consump- } \\
\text { tion }\end{array}$ \\
\hline
\end{tabular}

Table 1: Key elements of early diagnosis and screening (adapted from 'Guide to cancer early diagnosis. Geneva: World Health Organization; 2017') [2]. 
WHO global strategy on people-centered and integrated health services (2015) has mentioned that patients with no or minimal delay ( $<3$ months) experienced a greater likelihood of survival than patients with moderate delay (3 - 6 months) [8,9]. This establishes the fact that reducing delays in diagnosis and treatment planning can significantly impact the outcomes.

Such optimistic facts create a positive basis where Oral cancers, a relatively easily identifiable subcategory of cancers can be tackled effectively. Such situations firstly can benefit the patient population health wise and finance wise thereby consuming minimal treatment modalities and secondly saves the healthcare resources and makes them available for other individuals who also need them.

However, these strategies also have certain practical difficulties like limitations in resources and limited access to diagnostic tests and pathology can happen due to high volume target population. Other drawbacks include lack of follow-up, limited quality services, timely treatment and financial obstacles. Strategical Policies and programmes to overcome such obstacles should focus on improving the effectiveness of early diagnosis and cancer screening.

\section{Conclusion}

Early diagnosis and screening when involved can become a robust method to reduce the high numbers of cancer fatalities. Very common Cancer subtypes like oral Cancers can get commendable benefits owing to the ease of diagnosis and screening thereby reducing the mortality and complications of treatment involved.

\section{Bibliography}

1. WHO Cancer Prevention (2020).

2. Cancer control: early detection. WHO Guide for effective programmes. Geneva: World Health Organization (2007).

3. Guide to cancer early diagnosis. Geneva: World Health Organization (2017).

4. Taplin SH., et al. "Screening". In: Change AE, Ganz PA, Hayes DF, Kinsella TJ, Pass HI Schiller JH., et al. "Oncology: EvidenceBased Approach. New York, NY: Springer Science+Business Media (2006): 317-340.

5. WHO Position paper on mammography screening. Geneva: World Health Organization (2014).

6. Stockton D., et al. "Retrospective study of reasons for improved survival in patients with breast cancer in east Anglia: earlier diagnosis or better treatment". British Medical Journal 314.7079 (1997): 472-475.
7. Shulman LN., et al. "Breast cancer in developing countries: opportunities for improved survival". Journal of Oncology (2010): 595167.

8. Richards MA., et al. "Influence of delay on survival in patients with breast cancer: a systematic review". Lancet 353.9159 (1999): 1119-1126.

9. Breast cancer screening: IARC Handbook of cancer prevention, volume 15. Lyon, France: International Agency for Research on Cancer 15 (2016).

Volume 4 Issue 7 July 2021

(C) All rights are reserved by Sundaram Rajaram and

\section{Gauthami Sundar.}

